\section{Evaluation of Spanish research}

SIR - The report by Oscar G. Segurado (Nature 366, 9; 1993) on the Spanish Biological Research Centre (CIB) must be seen in relation to the new policies on evaluation and reorganization being implemented in the Spanish Council for Scientific Research (CSIC) as a whole.

There have been important changes in Spanish science and technology since 1983, notably new laws regulating universities and public research organizations. At the same time, resources for research have increased considerably; between 1983 and 1990, the percentage of gross national product devoted to research and development rose from 0.6 to 0.92 , the number of researchers increased from 1.0 to 2.5 per 1,000 of active population and there are new procedures to evaluate the scientific activity of researchers and research groups.

The CSIC, created in 1939, is the largest public research organization in Spain and covers almost all fields in the natural and social sciences as well as the humanities. CSIC researchers number 6 per cent of the Spanish total, but their output is 20.6 per cent of the total.

CSIC has sought to adapt to all these changes by a new set of rules (adopted a year ago) aimed at a more efficient and flexible organizational structure, improving scientific performance and facilitating cooperation with universities and other research institutions. Research institutes and centres are now considered the most important parts of CSIC's structure. Their directors now have the power to organize and supervise their activities. They have more power than before, but the researchers and staff personnel directly participate in the election of the directors within the institutes and centres. There is also a procedure allowing institute members to monitor management decisions. These changes in the directors' role were necessary to achieve more efficient management.

Before the approval of the new rules, most of the scientific personnel consulted accepted these changes. In the past three years, evaluations have been carried out affecting 28 institutes, 500 researchers, 900 staff members and 400 graduate students. As a result, five institutes have been closed down, six merged, four reorganized and six new ones created. Decisions have not yet been taken in the remaining cases.

Thus, the CSIC, like any other research institution, must solve problems arising from reallocation of scientific personnel within or between institutes. A detailed study is made in order to adopt the most convenient solution, and to avoid creating additional problems that might interfere with the normal development of the re- search work. The first solution proposed is not always adopted; the advisory and executive bodies examine alternative solutions that may be more appropriate. In the case of the CIB, the decision fits in better with these criteria and was not taken in response to pressure from any scientific union.

The CSIC stands firm in its intention to implement new evaluation and reorganization policies for its institutes and centres. What occurred in the CIB must not in any way be understood as a retreat or a threat to its position. It is simply one more case where these new policies have been implemented to improve the efficiency of our organization.

\section{José M. Mato}

(President)

Consejo Superior de

Investigaciones Cientificas,

Calle Serrano 117,

28006 Madrid,

Spain

SIR - Segurado points to important elements of concern about the future of research institutions in Spain. Although it is obvious that the new CSIC rules increase the authority of the president and of the institute directors, the president has always been able (and continues to be able) to boost particular fields of research in the most effective way, by deciding on the distribution of new positions (including those for internal promotion) among the different disciplines and by directly appointing the members of the selection committees.

Moreover, external evaluations are not new in the CSIC. The Cajal Institute, for example, to which Segurado refers, avoided dissolution in 1982 after two officially appointed external referees recommended support. The institute has had an external advisory committee ever since, but the evaluation in January 1992 was an internal one. It is ironic that such a delicate decision on personnel policy was taken after only an internal evaluation and so late in the day.

The CIB's external evaluation committee has now, according to Segurado, pointed out significant deficiencies that, interestingly, were also detected in the Cajal Institute by its external advisory committee several years ago. Leaving aside the urgent need for appointing new, well-trained scientific personnel, the committee also calls for breaking the isolation of the research groups and for defining common strategies.

Letters submitted for Correspondence should be typed, doubled-spaced, on one side of the paper only.
These objectives will hardly be attainable if the new CSIC rules are applied in the coercive manner described by Segurado. They may be fulfilled, however, if the CSIC encourages the application of the positive aspects of the new rules which, among others, include more efficient mechanisms to increase mobility between the CSIC and the universities.

Alfonso Fairén

Instituto Cajal, CSIC,

Doctor Arce 37,

28002 Madrid,

Spain

\section{Setting the record straight}

SIR - Luis Angel Fernández's News article (Nature 365, 684; 1993) may give a misleading impression.

He says that, in 1990, problems encountered in the course of an experiment involving genetically engineered plants carried out by the Catalan government's Institute of Agriculture meant that the crop being experimented on had to be burnt.

The Institut de Recerca i Tecnologia Agroalimentàries or IRTA (Institute for Food and Agricultural Research and Technology) is a public-sector company belonging to the Catalan government whose main activity is in the field of scientific research and technology transfer relating to agriculture and food. We therefore feel that "the Catalan government's Institute of Agriculture" will be understood as being IRTA.

The experiments referred to in the article were carried out in 1988 in the context of a research contract with the Belgian company Plant Genetic Systems under the direction of Dr Pere Arús, head of our department of plant genetics.

This contract was concluded on the basis of a research agreement approved by both parties which laid down and programmed not only the manipulation of the vegetable material, but also its subsequent destruction by boiling or burning. All the statutory requirments laid down by the relevant authorities (Ministry of Agriculture of Spain and Department of Agriculture of Catalonia) were observed.

At no time did anything occur that was untoward or that might have caused any risk or harm. The contract was fulfilled, the vegetable matter was destroyed as stipulated and the findings were in line with expectations.

Josep Tarragó

(Director General)

Institut de Recerca

iTecnologia Agroalimentàries,

Passeig de Gràcia 44,

08007 Barcelona,

Spain 